\title{
Liquefaction performances of bread crusts in subcritical water
}

\author{
Yuzhen Wang, Zhuan Liu, Changqing Fang, Zeyu Zhang, Li Xie \\ Shaanxi Provincial Key Laboratory of Printing and Packaging Engineering, Xi'an University of \\ Technology, Xi'an, Shaanxi, 710048, China
}

\begin{abstract}
Hydrothermal liquefaction of bread crusts in subcritical water were performed in a micro-batch reactor. The influences of temperature $\left(300-360{ }^{\circ} \mathrm{C}\right)$ and residence time $(10-30 \mathrm{~min})$ on bio-oil yield, boiling point distribution and functional groups in bio-oil were investigated. The results showed that bio-oil yield increased with increasing temperature and reaction time. Maximum bio-oil yield of $22.69 \mathrm{wt} \%$ was obtained at $360^{\circ} \mathrm{C}$, $30 \mathrm{~min}$. The longer reaction time promoted the degradation of diesel to jet fuel and naphtha. The naphtha (C7-10) and jet fuel (C11-C15) increased to $29.9 \%, 51.82 \%$ at $30 \mathrm{~min}$ from $20.49 \%$ and $36.14 \%$, respectively. FT-IR analysis showed that esters, ketones, amides, acids and aldehydes were present in the bio-oil.
\end{abstract}

\section{Introduction}

Food waste is solid or liquid organic waste produced in the process of daily diet. Fermentation and decay will occur at the action of microorganisms. If the food waste is not properly treated, it will not only harm people's lives and health, but also cause environmental pollution and pollute the atmosphere and water sources. The main treatment process is landfill, however, it covers large amount of land, and is prone to create secondary pollution, such as the landfill leachate ${ }^{[1]}$.Hydrothermal liquefaction (HTL) in subcritical water is a process that can directly convert wet organic wastes into bio-oil avoiding the energy-intensive and expensive dry step required in pyrolysis ${ }^{[2]}$. As the main component of food waste is the cereals, which are mainly composed of starch, we selected bread crusts as the research object, the effects of the reaction temperature and time on the bio-oil and solid residue yield were studied. And also the components of the bio-oil were investigated.

\section{Experimental}

\subsection{Materials}

Corresponding author: yzwang@xaut.edu.cn 
The bread crusts was first dried in the oven at $80^{\circ} \mathrm{C}$, and then was grinded to about 20 $30 \mu \mathrm{m}$.

\subsection{Procedures and separation of the products}

The experiments were performed in a micro-reactor. The reactor is made of $316 \mathrm{~L}$ stainless steel, and is designed to withstand a maximum temperature and pressure of $480{ }^{\circ} \mathrm{C}$ and $38 \mathrm{MPa}$, respectively. A certain amount of bread crusts and deionized water were charged into the reactor, and then the sealed reactor was placed in a tube furnace to heating to the reaction temperature. After the reaction time was reached, the reactor was taken out and cooled in cold water immediately. The experimental process was shown in Fig.1. The products in the reactor were washed with $9 \mathrm{ml}$ dichloromethane, and then the products was subjected to solid-liquid separation by a centrifuge. Finally, the dichloromethane in the solution was blown away with a nitrogen blower, and the rest liquid was bio-oil. The separated solid residue was dried and weighed in an oven at $80{ }^{\circ} \mathrm{C}$.

The bio-oil yield and residue yield are calculated as the mass ratio of bio-oil to reacted bread crusts, and ratio of solid residue bio-oil to reacted bread crusts, respectively.

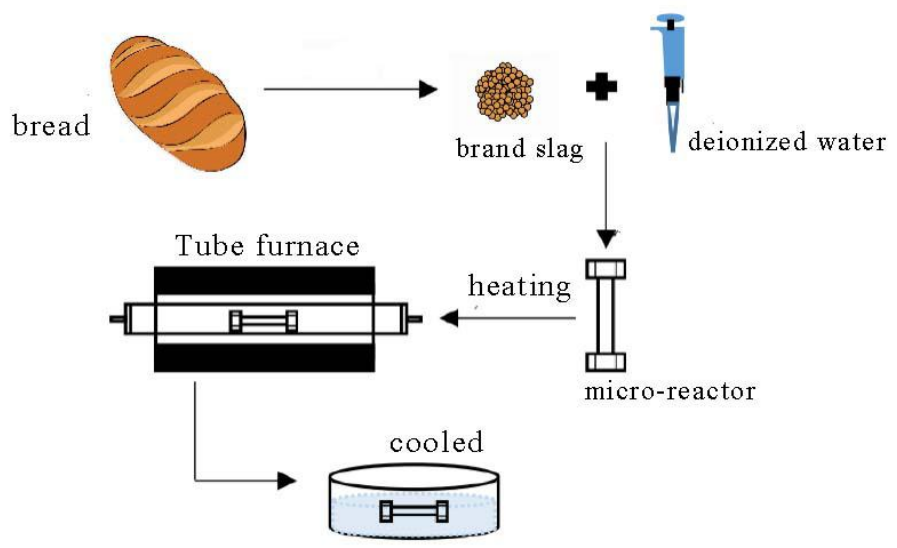

Fig.1 Experimental procedures

\subsection{Analysis}

Thermogravimetry analysis (TGA) (209 F3 Tarsus, Nietzsche, Germany) was used to evaluate the boiling point distribution of the bio-oil. Samples were taken at a temperature of $25^{\circ} \mathrm{C}$ to $550^{\circ} \mathrm{C}$ in an $\mathrm{N}_{2}$ atmosphere of $60.0 \mathrm{ml} / \mathrm{min}$ at $10^{\circ} \mathrm{C} / \mathrm{min}$. Fourier infrared spectrometer (FT-IR) (Shimadzu FTIR-8400S) was used to determine the functional groups contained in the bio-oil, the measurement frequency range is $4000-500 \mathrm{~cm}^{-1}$.

\section{Results and discussions}

\subsection{Effect of temperature and reaction time on bio-oil yield}

The effects of different reaction temperature and reaction time operated at $20 \mathrm{MPa}$ on the bio-oil yield and residue yield of bread residue in subcritical water are shown in Fig.2. The reactant concentration kept at $20 \mathrm{wt} \%$. It can be clearly observed that the bio-oil yield 
increased obviously with the increasing temperature from $300^{\circ} \mathrm{C}$ to $360^{\circ} \mathrm{C}$. And the solid residue decreased accordingly. The bio-oil yield at $300^{\circ} \mathrm{C}, 330^{\circ} \mathrm{C}$ and $360^{\circ} \mathrm{C}$ were $15.77 \%$, $20.39 \%$, and $22.69 \%$, at the reaction time of $30 \mathrm{~min}$, respectively. Higher temperature promoted the degradation of starch and glucose in the bread crusts ${ }^{[3,4,5]}$.

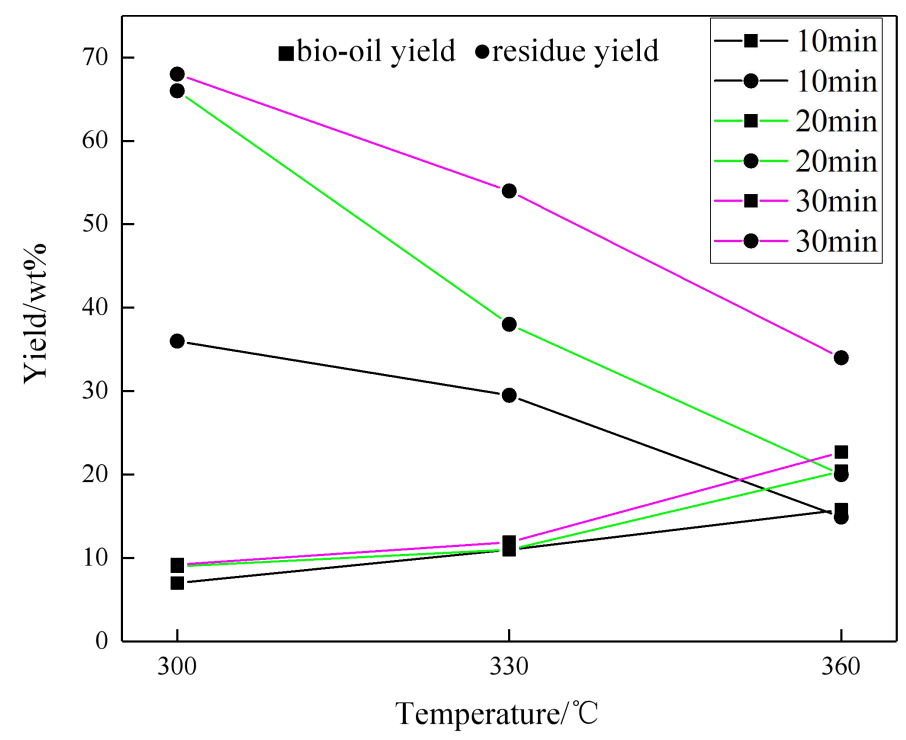

Fig.2 Changes of bio-oil and residue yield with temperature and reaction time

In the reaction time range of $10-30 \mathrm{~min}$, the bio-oil yield increased with the reaction, this means that the reaction was not completed before $30 \mathrm{~min}$. The variation trend of residue yield was opposite. Similar results were also found in the HTL of swine manure ${ }^{[4]}$, military surrogate waste ${ }^{[1]}$ and Dunaliella salina ${ }^{[6]}$.

\subsection{Boiling point distribution in the bio-oil}

The boiling point distributions of bio-oil were evaluated by the TGA, which can be viewed as a miniature "distillation" [7]. Fig.3 showed the boiling point distribution and thermal conversion properties of bio-oil operated at $360^{\circ} \mathrm{C}$ for $20 \mathrm{~min}$ and $30 \mathrm{~min}$. The fuel fractions with the boiling point range of $100-200{ }^{\circ} \mathrm{C}, 200-300{ }^{\circ} \mathrm{C}$, and $300-550{ }^{\circ} \mathrm{C},>550{ }^{\circ}$ $\mathrm{C}$ were defined as naphtha, jet fuel, diesel and vacuum residue, respectively, as shown in Table 1. Results showed that the naphtha(C7-10) and jet fuel (C11-C15) increased greatly at $30 \mathrm{~min}$ compared with that at $20 \mathrm{~min}$, and the value climbed from $20.49 \%$ to $29.9 \%$, and $36.14 \%$ to $51.82 \%$. While the content of diesel (C16-C47) decreased from $41.78 \%$ to $16.97 \%$ from $20 \mathrm{~min}$ to $30 \mathrm{~min}$. The results indicated that large molecular compounds were degraded to smaller molecular compounds with the increasing reaction time. The content of vacuum residue $(>\mathrm{C} 48)$ were very low at $20 \mathrm{~min}$ and $30 \mathrm{~min}$, which mean that the intermediates rarely polymerized to the coking products. 

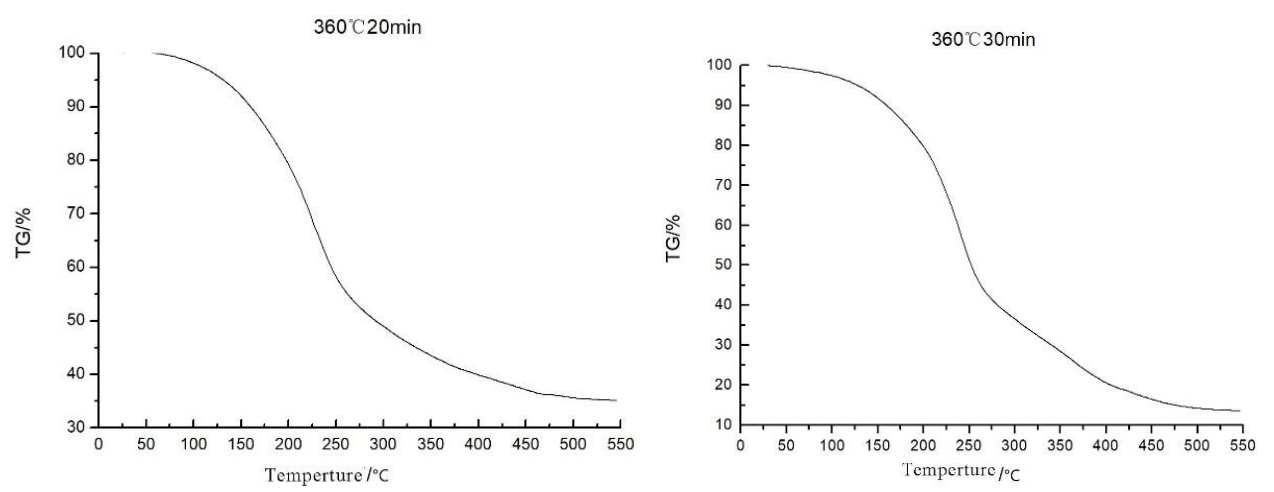

Fig.3 TG curves of bio-oil

Table 1 Boiling point distribution of bio-oil

\begin{tabular}{|c|c|c|c|c|}
\hline \multirow{2}{*}{ Time/min } & $\begin{array}{c}\text { Naphtha } \\
\left(<200{ }^{\circ} \mathrm{C}\right)\end{array}$ & $\begin{array}{c}\text { Jet fuel } \\
\left(200-350{ }^{\circ} \mathrm{C}\right) \\
\mathrm{C} 7-\mathrm{C} 10\end{array}$ & $\begin{array}{c}\text { Diesel } \\
\left(350-500{ }^{\circ} \mathrm{C}\right) \\
\mathrm{C} 11-\mathrm{C} 15\end{array}$ & $\begin{array}{c}\text { Vacuum residue } \\
\left(>500{ }^{\circ} \mathrm{C}\right) \\
>\mathrm{C} 16-\mathrm{C} 47\end{array}$ \\
\hline 20 & $20.49 \%$ & $36.14 \%$ & $42.78 \%$ & $0.47 \%$ \\
\hline 30 & $29.90 \%$ & $51.82 \%$ & $16.97 \%$ & $0.73 \%$ \\
\hline
\end{tabular}

\subsection{Functional groups in the bio-oils}

The FT-IR of bio-oil is shown in Fig.4. It can be seen that the temperature and reaction time showed little influence on the vibration peaks of the infrared spectrum, which indicating that the types of functional groups in the bio-oil are similar. The vibration peaks at $3200-3500 \mathrm{~cm}^{-1}$ indicating the $\mathrm{O}-\mathrm{H}$ groups, which reflected the presence of amines, phenols, and alcohols. The $2800-2950 \mathrm{~cm}^{-1}$ represents the stretching vibration peak of C-H. Around $1700 \mathrm{~cm}^{-1}$ is the $\mathrm{C}=\mathrm{O}$ stretching vibration peak, which means that esters, ketones, amides, acids and aldehydes may present. Around $1600 \mathrm{~cm}^{-1}$ and $1520 \mathrm{~cm}^{-1}$ should be the bending vibration peaks of $\mathrm{N}-\mathrm{H}$ and $-\mathrm{NH}_{2}$, which represent amides and amines. Around $1500 \mathrm{~cm}^{-1}$ is the $\mathrm{C}=\mathrm{C}$ stretching vibration peak, which represents the benzene rings. Around $1380 \mathrm{~cm}^{-1}$ and $1460 \mathrm{~cm}^{-1}$ are $-\mathrm{CH}_{2}$ bending vibration peaks and $-\mathrm{CH}_{3}$ bending vibration peaks, which represent saturated $\mathrm{C}-\mathrm{H} .1300 \mathrm{~cm}^{-1}$ to $1000 \mathrm{~cm}^{-1}$ are $\mathrm{C}-\mathrm{O}$ stretching vibration peaks, which are the strongest peaks in this region. They are easier to identify and represent phenols, acids, esters, and alcohols.

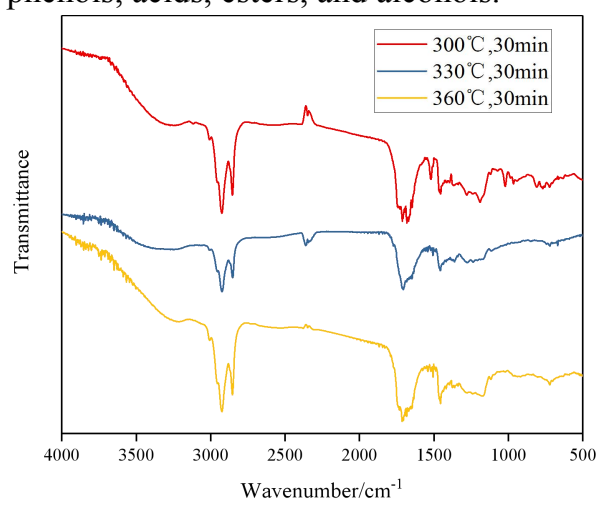

(a)

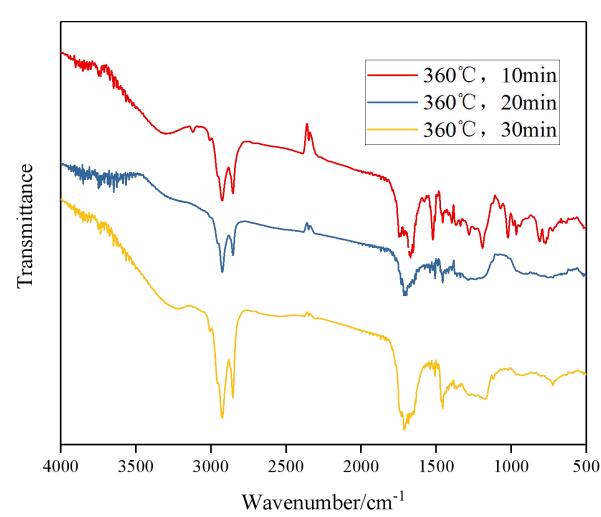

(b)

Fig.4 FT-IR spectra of bio-oil obtained at (a) $300-360^{\circ} \mathrm{C}, 30 \mathrm{~min}$ (b) $360^{\circ} \mathrm{C}, 10-30 \mathrm{~min}$. 


\section{Conclusions}

The hydrothermal liquefaction of bread crusts were operated in the micro-reactor at 300-360 ${ }^{\circ} \mathrm{C}$ and 10-30 min. The effects of temperature and reaction time on the bio-oil yield and components of the bio-oil were investigated. The results showed that temperature and reaction time showed positive effect on the bio-oil yield. At $360{ }^{\circ} \mathrm{C}, 30 \mathrm{~min}$, maximum bio-oil yield of $22.69 \mathrm{wt} \%$ can be obtained. Longer reaction time promoted the degradation of diesel to jet fuel and naphtha. The naphtha (C7-10) and jet fuel (C11-C15) increased to $29.9 \%, 51.82 \%$ at $30 \mathrm{~min}$ from $20.49 \%$ and $36.14 \%$, respectively. FT-IR analysis showed that esters, ketones, amides, acids and aldehydes were present in the bio-oil.

\section{References}

[1] D.J. Zastrow, P.A. Jennings, Florida Institute Techno (2013).

[2] R. Chand, V.B. Borugadda, M. Qiu, A.K. Dalai, Appl. Energy , 254. 113679(2019).

[3] Y. Qu, Z.D. Liu, Z.B. Zhu, et al. J. Solar. Energy. 37, 1333(2016).

[4] G.Yu, Y. Zhang, L. Schideman, et al. Transactions of the ASABE, 54, 239-246(2011).

[5] Y.H. Chan, A.T. Quitain, S.Yusup, et al. J. Energy. Inst, 91(5): 721-732(2018).

[6] B. Eboibi, D. Lewis, P. Ashman.Bioresour. Technol. 170, 20-29(2014).

[7] W.T. Chen, Y.H. Zhang, J.X. Zhang, G .Yu, L.C. Schideman, P.Zhang, et al. Bioresour Technol 152,130-9(2014). 